\title{
REPLACEMENT OF A CUTICULAR APOPHYSIS \\ IN LARVAL SARCOPHAGA BULLATA \\ (DIPTERA, INSECTA) DURING MOULTING
}

\author{
By Mandy Kotzman \\ Department of Zoology, \\ Monash University, Clayton, Victoria, 3168 AUSTRALIA ${ }^{1}$
}

\section{INTRODUCTION}

In arthropods, growth of hard body parts is achieved during periodic moults. At such times, a new cuticle is formed and, after some reabsorption, the old is discarded. For much of the exoskeleton, which is bounded externally by the epidermis, the sequence of events in moulting has been well documented (Neville 1975, Hackman 1971, Hepburn 1976, Hepburn 1985). Replacement of some cuticular structures would appear to be more complex. Apophyses are solid internal projections of cuticle, frequently forming muscle attachments, which arise from either the external body wall or the linings of the fore- or hind-gut (Neville 1975, Hepburn 1976). Embryological formation of these structures produces solid pieces of cuticle surrounded by epidermal tissue. It would seem that following the first and subsequent ecdyses, secretion of new cuticle from the surrounding epidermis would produce an invaginated fold of cuticle rather than the single structure of a typical apophysis. The manner in which apophyses can be conserved during moulting is described in this paper.

\section{METHODS}

Larval "heads" of Sarcophaga bullata Parker were fixed (Karnovsky 1965) and post-fixed prior to embedding in hard resin (Spurr 1969). Transverse sections of $1 \mu \mathrm{m}$ and about $60 \mathrm{~nm}$ were obtained for light and transmission electron microscopy respectively. Whole larval "heads" were also cleared in 5\% potassium hydroxide, dehydrated in $100 \%$ ethanol and mounted in euparal (Gurr Ltd.).

'Present address: Mitrani Center for Desert Ecology, Jacob Blaustein Institute for Desert Research, Midreshet Sede Boqer, Israel, 84993

*Manuscript received by the editor June 24, 1989. 


\section{Results AND Discussion}

The larval mouthparts of the flesh-fly Sarcophaga bullata have large apophyses (forming the pharyngeal sclerite) which arise from the foregut as two wings (Fig. 1). This sclerite provides support for most of the muscles which expand the pharynx during feeding. Larvae, in various stages of development, were obtained from cultures of the fly (Roberts 1976). In instar 1, the solid nature of the sclerotised cuticular "wings" was clearly evident (Fig. 2). Prior to ecdysis, apolysis and cuticle secretion were visible on both sides of the wings along the margins of the epidermis (Fig. 3a). Following ecdysis, filaments of cuticle bridged the ecdysial space and linked the opposing surfaces of new cuticle (Fig. 3b). By the middle of instar II, the "wings" of the pharyngeal sclerite had become singlelayered structures, although they remained vesicular rather than becoming solid (Fig. 4). Thus, rather than becoming a bilayered structure following ecdysis, the apophysis was retained in a form similar to that derived embryologically.

The precise nature of the newly-secreted cuticle was not determined, nor was the nature of the cuticular filaments which bridged the ecdysial space. Nevertheless, the clear margins of the new cuticle which were visible prior to ecdysis were not apparent after ecdysis. This suggested that rather than simple infilling of the ecdysial space with cuticle secreted through the existing layers of new cuticle, some disruption of the first layer had occurred. Regulation of the bridging process may involve the initial deposition of specialised cuticle

Explanation of Figures 1-4 (facing page).

Larval mouthparts of Sarcophaga bullata.

Fig. 1. Mid instar I, lateral view, with the position of the transverse sections indicated. Whole mount, Nomarski Interference Contrast optics. Scale bar: $100 \mu \mathrm{m}$. mh, mouthhooks; $p$, pharynx; ps, pharyngeal sclerite.

Figs. 2-4. Transverse sections of the pharyngeal sclerite.

Fig. 2. Mid Instar I. a) Entire sclerite, the position of the section in 2.b is indicated. Scale bar: $10 \mu \mathrm{m}$. b) Detail of a "wing" of the pharyngeal sclerite, transmission electron micrograph (TEM). Scale bar: $1 \mu \mathrm{m}$. c, cuticle; e, epidermis.

Fig. 3. TEM from a similar position as 2.b. a) Late instar I just prior to ecdysis, arrows indicate the layers of newly-secreted cuticle. Scale bar: $1 \mu \mathrm{m}$. b) early instar II just after ecdysis. Scale bar: $1 \mu \mathrm{m}$. cf, cuticular filaments; e, epidermis.

Fig. 4. Mid instar II. a) Entire sclerite, indicating the position of 4.b. Scale bar: $10 \mu \mathrm{m}$. b) detail of a "wing" of the pharyngeal sclerite, TEM. Scale bar: $1 \mu \mathrm{m}$. c, cuticle; e, epidermis. 

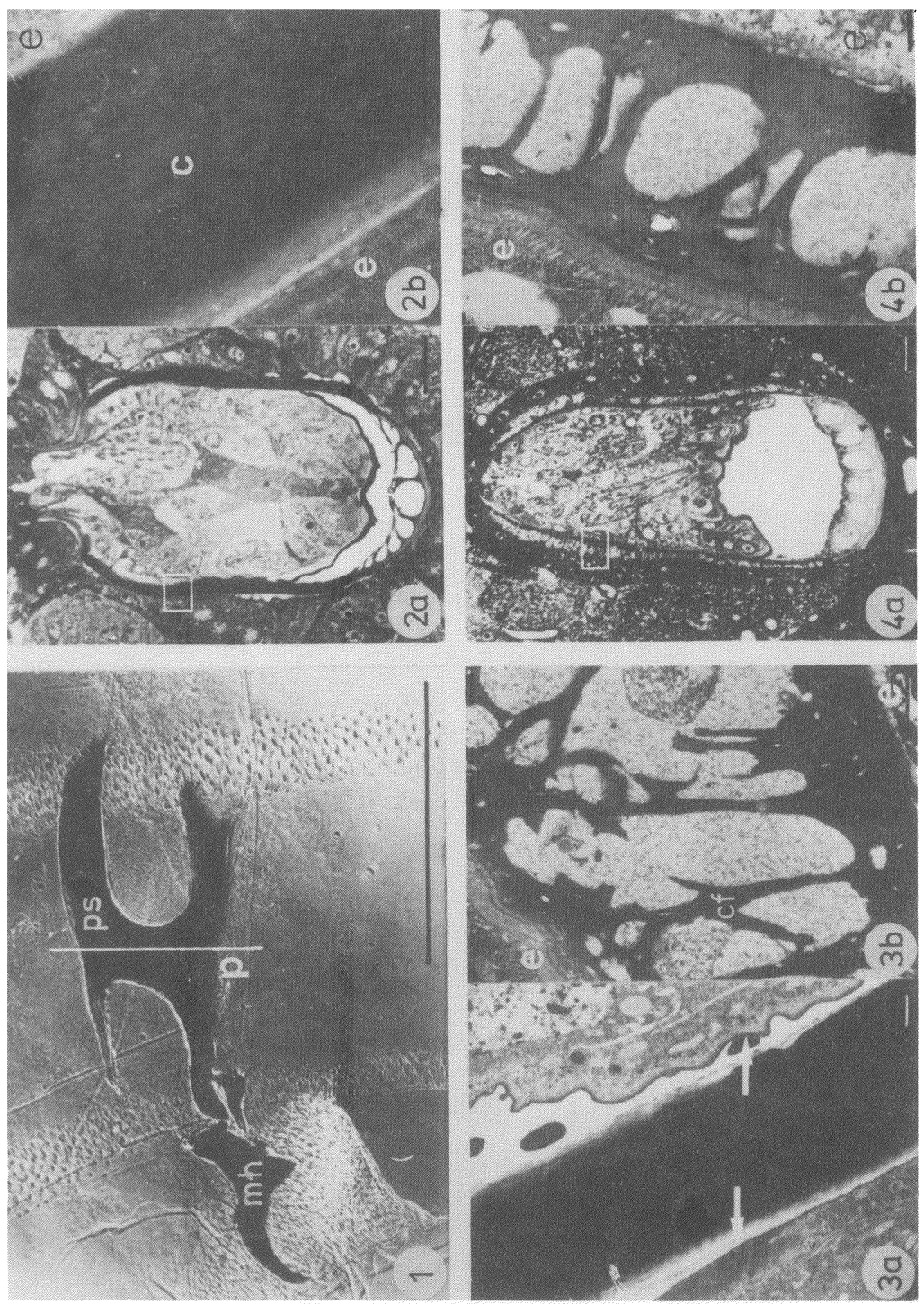
layers followed by post-ecdysial secretion of products which promote bridging between these layers. This process may be regulated by epidermal cells, and could potentially be achieved through pore canals (Neville 1975), although these structures were not apparent in the material used here, and are reportedly absent in the exocuticle of these flies (Filshie 1982). Alternatively, it is possible that such bridging is a natural consequence of close association between layers of newly secreted cuticle which is sclerotised after ecdysis. In insect wing development, cytoplasmic bridges (Mayer 1896) or hypodermal cells (containing bundles of micro-filaments) seem to hold the new layers of cuticle together while the wings are expanded by elevated haemolymph pressure (Seligman et al. 1982). Following the withdrawal of the hypodermis and the haemolymph, the two layers of cuticle may be similarly bridged by cuticle. However, in the case of insect wings, such a process would not include further cuticle deposition in the absence of the hypodermis. Indeed, if folds of new cuticle are not unravelled or dissociated by post-ecdysial expansion, bridging may occur spontaneously. Failure to moult successfully is a common cause of death in laboratory-reared arthropods. In general, such failure has been attributed to incomplete formation of the new cuticle (for various reasons), or an inability to complete ecdysis prior to hardening of the new cuticle in its unexpanded form. Bridging of the new cuticle along touching surfaces may explain, at least in part, the inability of arthropods to moult successfully when the process exceeds a critical time limit. A closer inspection of the structure of cuticle in individuals who have failed to moult successfully may well illuminate the mechanism underlying the bridging process involved in the replacement of apophyses.

\section{SUMMARY}

Conservation of the structure of apophyses during moulting was investigated using larval mouthparts of the flesh-fly Sarcophaga bullata. Although the cuticle was secreted as a bilayered-fold around the apophysis prior to ecdysis, after ecdysis the opposing surfaces of the new cuticle were bridged by cuticular filaments to form a single structure. 


\section{ACKNOWLEDGEMENTS}

John Nailon is thanked for cutting the ultrathin sections for the TEM. I wish to thank David Dunkerley, Barry Filshie, John Gross and David Ward for their comments on earlier drafts of the manuscript.

\section{Literature Cited}

FilshiE, B. K. 1982. Fine structure of the Cuticle of Insects and Other Arthropods. pp. 281-412. In King \& Akai Eds. Insect Ultrastructure, Vol 1. Plenum Publ. New York \& London, Co.

HACKMAN, R. H. 1971. The integument of arthropoda. pp. 1-63. In M. Florkin ed. Chemical Zoology VI Arthropoda B. Academic Press, New York.

Hepburn, H. R. 1976 (Ed.) The Insect Integument. Elsevier Sci. Publ. Co., New York.

HePburn, H. R. 1985. Structure of the Integument. pp. 1-58. In G. A. Kerkut \& L. I. Gilbert eds. Comprehensive Insect Physiology, Biochemistry and Pharmacology, Vol 3. Pergamon Press Oxford.

KARNOvSKY, M. J. 1965. A formaldehyde-glutaraldehyde fixative of high osmolality for use in electron microscopy. J. Cell Biol. 27: 137-138.

MAYER, A. G. 1896. The development of wing scales and their pigment in butterflies and moths. Bull. Mus. Comp. Zool. 26: 209-236.

Neville, A. C. 1975. Biology of Arthropod cuticle. Springer-Verlag, New York.

RoBerts, B. 1976. Larval development of an Australian flesh-fly. Ann. Entmol. Soc. Am. 69: 158-165.

Seligman, I. M., Filshie, B. K., Doy, F. A. and Crossley, A. C. 1975. Hormonal control of morphogenetic cell death of the wing hypodermis in Lucinia cuprina Tissue \& Cell 2: 281-296.

SPURR, A. R. 1969. A low viscosity epoxy resin embedding medium for electron microscopy. J. Ultra Structure 26: 31-43. 

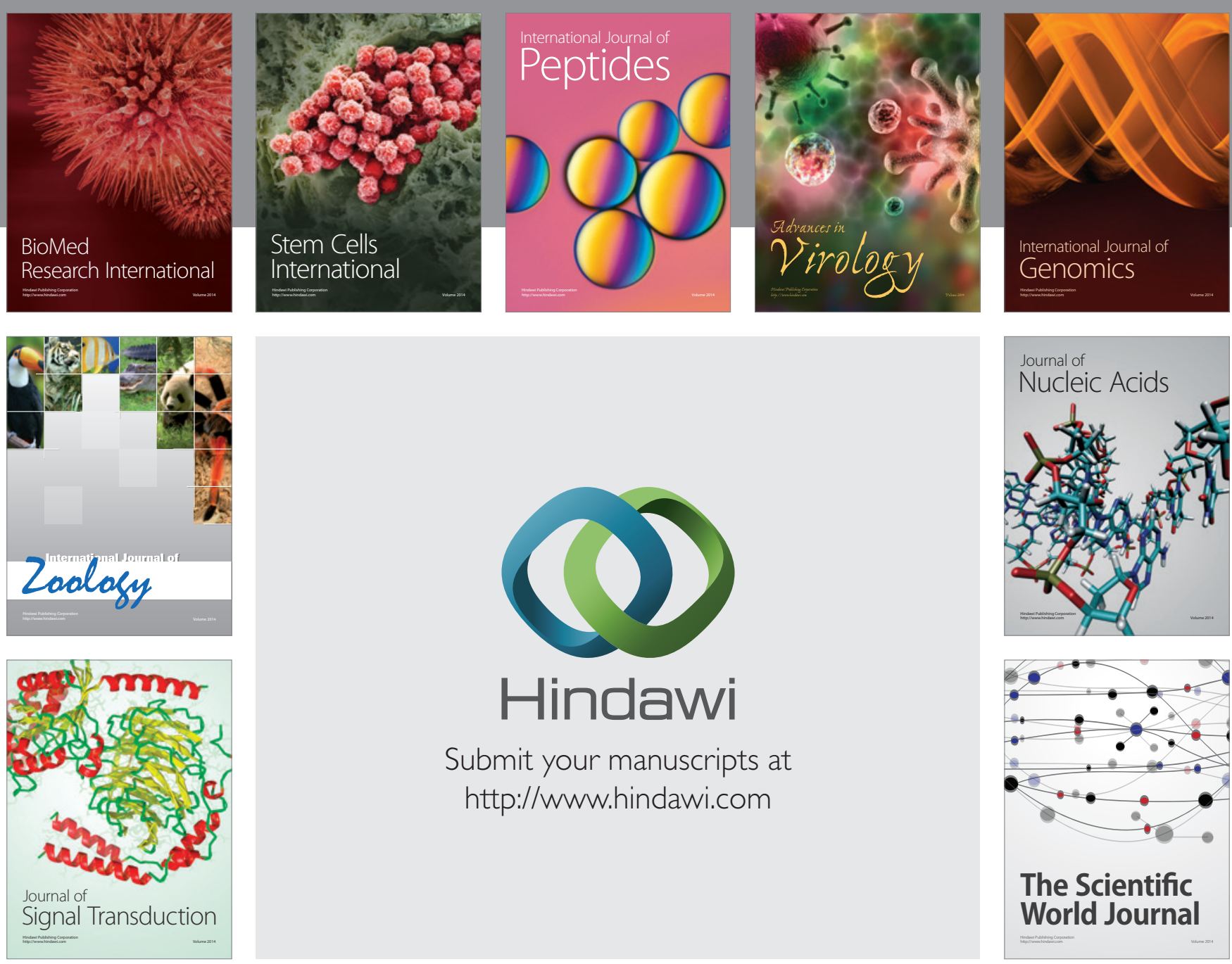

Submit your manuscripts at

http://www.hindawi.com
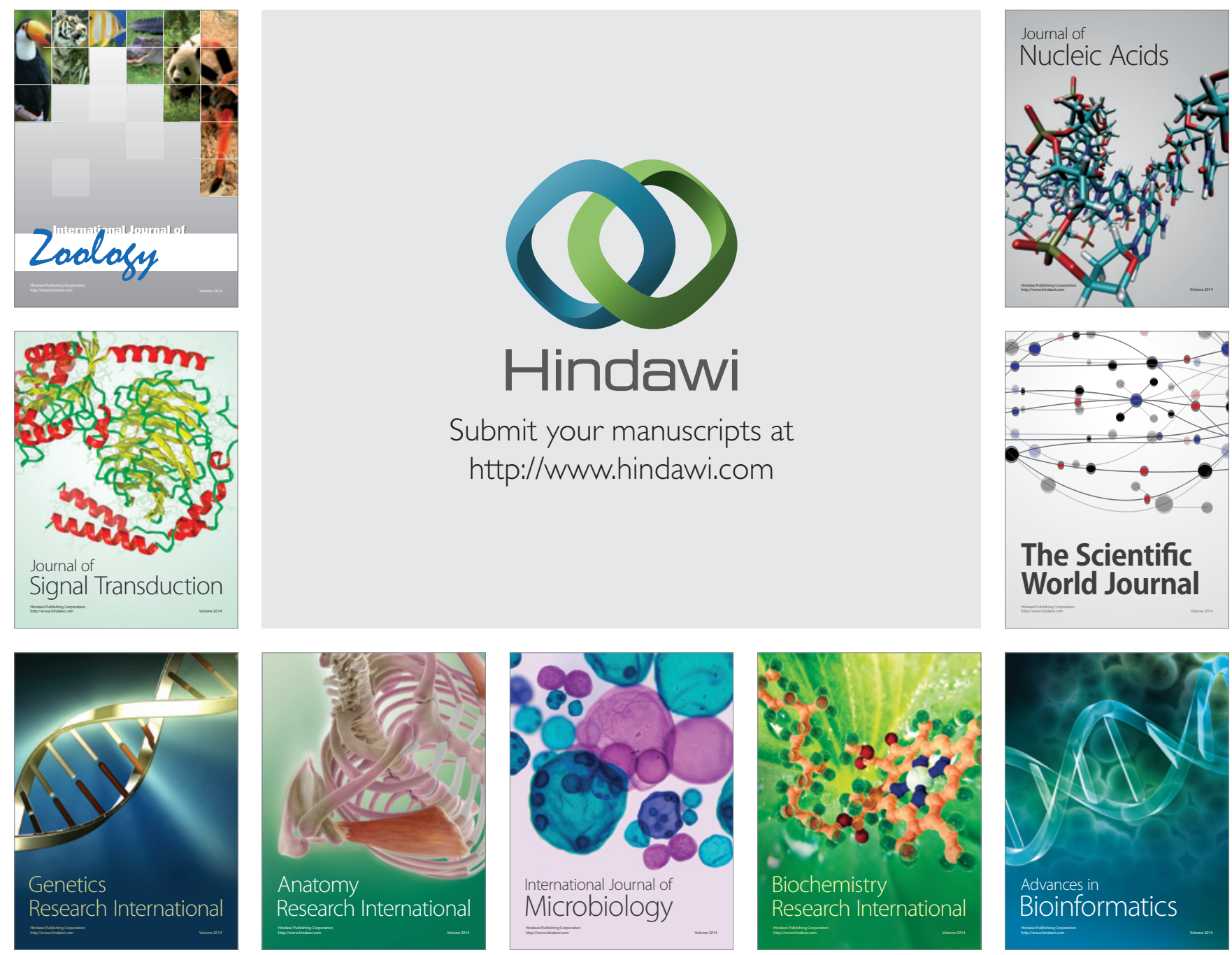

The Scientific World Journal
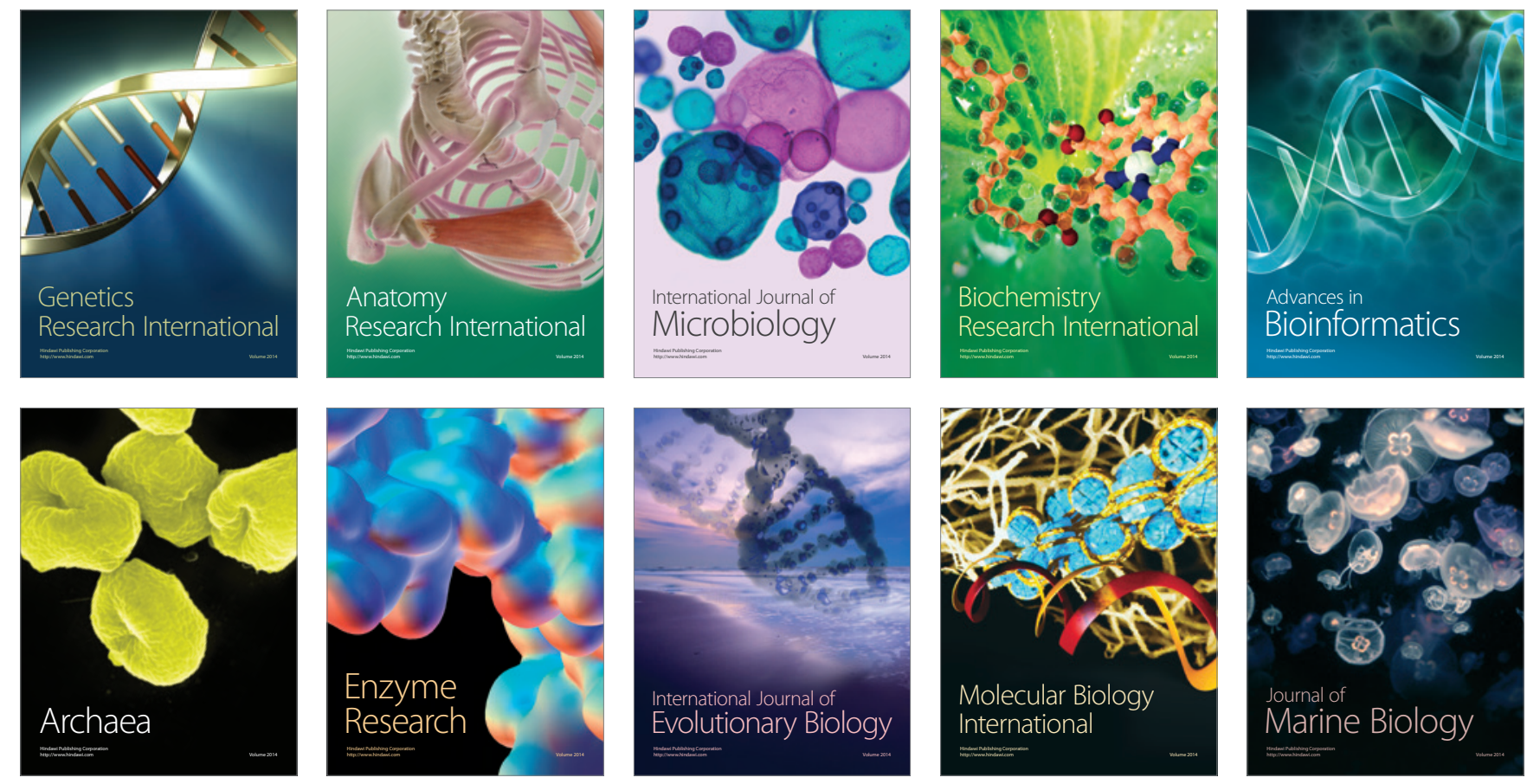